\title{
Prostate Phyllodes Tumor
}

National Cancer Institute

\section{Source}

National Cancer Institute. Prostate Phyllodes Tumor. NCI Thesaurus. Code C7574.

An unusual, biphasic benign or malignant neoplasm that arises from the prostate gland.

It is characterized by the presence of an epithelial glandular component and a

proliferating stroma. 